\title{
Dynamism of Beauty Pageantry: The Conceptual Frame of Ghana's Most Beautiful Pageant
}

\author{
Scholastica Wompakeah Azuah ${ }^{1} \quad$ Simon-Peter Kafui Aheto ${ }^{2} \quad$ Kwabena Asubonteng ${ }^{3}$ \\ 1.Department of Fashion Design and Technology, Takoradi Technical University, Ghana \\ 2.Department of Distance Education, University of Ghana, Legon \\ 3.Department of Integrated Rural Art and Industry, Kwame Nkrumah University of Science and Technology, \\ Ghana
}

\begin{abstract}
In the African continent and for that matter Ghana, little is written or known about beauty pageantry. Viewers for the past 14 years, watch Ghana's Most Beautiful (GMB) yearly without enough documentation on the relevance of its concept. This article expounds the main concept of the pageant and its possible significance on the Ghanaian society. Descriptive research design was employed to obtain answers to questions regarding its activities. The Population consisted of participants from contestants' hometowns while the sample was purposively selected according to various stakeholders involved. Research instruments employed were observation, interviews and content analyses. The study revealed that the pageant's concept did not only align with its focus, but also promoted businesses and adoption of cultural values. It is a yearly event full of educative and brilliant scenes geared towards possible live transformations. It is recommended that GMB continues to evaluate its yearly events to avoid deviation from concept into undesired practices.
\end{abstract}

Keywords: Dynamism, Beauty Pageantry, Conceptual Frame, Ghana's Most Beautiful

DOI: $10.7176 /$ RHSS/11-16-06

Publication date:August $31^{\text {st }} 2021$

\section{Introduction}

For centuries the question of beauty and how it is defined was explored. The "formula" for beauty has been researched by scholars of all fields of study. Darwin in his book "The Descent of Man" wrote, "It is certainly not true that any common standard of beauty with respect to the human body exists in the mind of man. $\mathrm{He}$ questioned: what processes are followed in deciding who is attractive and who is not? Society has many different descriptions of what is beautiful, and beauty is determined when one is attracted to the other but do we determine who to be drawn to consciously? or the answer lies in biology?".

This continues to suggest that more varied and personal definitions are given every day with regards to beauty standards. Melotti a fashion photographer, in her search for the definition around the world of beauty, employs us to think of how different things would be if every person agreed that the "heart is what is important". With respect to beauty everyone has his or her qualities (Coughlin, 2017). Beauty does not have a single property, but a collection of different properties of things in the world combined to give an experience of beauty.

A fashion object and what it does to provide satisfaction in the process varies but draws inspiration from its aim of production and fashioned outcomes must fit well with the event's mission. The object becomes more than just a work of art; it is also a form of recreation. "With regards to beauty, the pleasure in a feature that happened to be adaptive is what survived" (Chatterjee, 2017 p.77). Nevertheless, it is likely that in the course of time these preferences will be inherited.

Cope and Maloney, (2016) stated how fashion attempted to find attractiveness beyond the conscious level and to determine positions in which clothing may play roles in human interests. Scientists have discovered that symmetry plays a role in determining attraction. This can also begin to explain attractiveness from the most basic levels, but the question is what accounts for the worldwide differences in beauty standards? Within different societies and communities, the idea of beauty varies. Beauty is always associated to pageantry due to its presentation of colourful and attractive people and events. Studies in Langlois, Kalakanis, Rubenstein, Larson, Hallam, \& Smoot (2000) revealed that, in fact, attractive people are treated more favourably and psychologically balanced than unattractive people in general. In support of this theory, Langlois et al. (2000), a recent metaanalyst found that attractive adults are generally considered to be more occupationally and socially competent compared with unattractive ones. Deducing from the above discussions on beauty, one could confidently admit that it is vital in pageantry by reason of its psychological attributes and the power of attractiveness.

Beauty pageants are public elaborate, colourful and entertainment events of which young ladies are selected in a competitive manner. Queen of Bardhhaman in Chatterjee, (2016) describes beauty pageant as a competition which focuses mainly on contestants' beauty and other qualities. Traditionally they focus on judging and ranking contestant's personality and physical attributes. Therefore intelligence, talent, and ability of answering judges' questions satisfactorily aid in the definition of a contestant's beauty in a pageantry.

Consequently, every pageant must have a direction of which beauty is found within. Pageants in whichever 
form cannot exclude physical beauty since it is the first point of attraction. However, one's physique, outfits, modelling, talents, and intelligence alone should not form the criteria for determining a winner. Even though the presentation of oneself flawlessly and gracefully in front of others is a fantastic way of expressing selfconfidence that must be in line with the main objective of the event; it is not all about appearance.

Therefore, since beauty pageants are also wonderful platforms for recognizing charismatic and talented women, their activities should be tailored and directed to specific objectives. Just like athletes, contestants are trained to excel in performance by way of being fluent, charismatic, smart and emotionally balanced to win a crown.

Though Caves, (2000) mentioned that in pageantry hard work pays, luck is never underestimated. Though called beauty pageants, not every winner is the prettiest, for beauty is not all judged based on physical appearance. Nonetheless a beautiful contestant has one box naturally ticked. Judgement does not depend on selfqualities alone but the engagement of these to the fulfilment of a pageant's philosophy.

According to Swale, (2017) the importance of conceptual fashion has become recognised largely through the development of fashion studies in the past years, providing a more diverse range of approaches to fashion than traditional linear narratives of the past. Fashion covers a wider range of areas, from production to consumption, as well as systems of meaning and significance. Similarly, the practice of beauty pageant which connects with fashion is gradually towing that direction. Some pageantries such as Ghana's Most Beautiful and others have begun moving conceptually as against concentrating on the normal physical appearance approach.

In contemporary conceptual fashion, Hazel Clarke recognises the importance of process, when she identifies the predominance of ideas over appearance, innovation, experimentation and valuing statements that pose questions rather than answers. As such, standard can be referred to as a kind of strategy for design thinking, and hence concentrate on suitability of processes in the conceptualisation of activities.

In 2007, an insightful pageant culturally educative and with a national patronage called Ghana's Most Beautiful (GMB) pageant was launched by a television station (TV3) in Ghana. The pageant with the theme "Redefining Beauty to Promote National Unity and Development" is a reality show which originated from a 45 minute television programme on the Ghanaian culture called "Akwaaba". Later this was extended to all regions of Ghana for a wider knowledge of Ghanaian culture, a narration by one of the pageant organisers on $3^{\text {rd }}$ August 2016.

The annual event was an adaption of a beauty pageant in Malaysia called "Miss Malaysia" in 2007 with the main objective of showcasing Ghanaian cultural values through the female gender as a powerful symbol of communication. According to a GMB 2012 report, TV3 believes selecting a woman as the symbol and nature of fertility, culture, tradition, grace, power, elegance and national pride of Ghanaians would not only expose Ghanaian cultural values but also represents its beauty. Balogun, (2012) stated that in emerging nations, beauty pageants perform important dual roles by both creating more cosmopolitan view of femininity that firmly positions a nation in the international arena and unifying vision of a country's femininity within itself.

The pageant also sought to promote cultural awareness and preservation through the concept of fashion and to re-unite the nation by showcasing national distinctiveness and pride. Contestants from various ethnic groups of Ghana showcased and competed on their cultural practices.

The contestants were endorsed by their traditional leaders as ladies of character found fit to showcase traditions, cultural rites and the most beautiful sights of their regions. They went through a thirteen-week contest displaying their culture. These regional representatives were evicted based on performance through votes from the public ensuring every week, ladies remaining in the contest have more qualities to impact on people's lives as required of the fashion concepts. Organisers ensured selected ladies possess outstanding character and skills to bring out change in the Ghanaian society through their beauty.

In the African continent and for that matter Ghana, little is written or known about beauty pageantry resulting in mixed reactions among the general public about pageants, as a result of a mismatch between pageantry and their cultural beliefs. This article discusses the policy and main concept of Ghana's Most Beautiful pageant. The dynamism of beauty pageants such as GMB has been examined giving way to the establishment of a framework.

\section{Research Methodology}

The exploratory research design was employed to obtain information on the concept of GMB pageant on Ghanaian society. Population consisted of all participants of GMB pageants during 2016 to 2020 yearly events. Sample size was 48 respondents with sampling technique being purposive. Research instruments used were observation, interviews and content analyses. Content analyses were done based on data gathered on the pageant. It was applied in studying the phenomenon and explaining events in relation to pageant's vision. The input-out process model was applied in illustrating the frame of the beauty pageant. 


\section{Result Findings and Discussions}

Ghana beauty pageants began in 1957 when Osagyefo Dr Kwame Nkrumah was President. Miss Monica Amekoafia was crowned as first beauty queen after Ghana's independence. The country's largest and oldest national beauty pageant "Miss Ghana" provides a forum for the single Ghanaian woman to impact positively on her community. Since the introduction of the first pageant in the country, more deserving intelligent young ladies have been successfully crowned in other similar pageants. Few that come to mind are Miss Malaika, Miss Tourism Ghana, Miss Earth and others in various institutions and festivals (Frimpong, 2016).

All other pageants came with unique set of approaches in addressing various issues. Contributions made gave the country a very good image on international platforms which are greatly essential to the development of Ghana. According to Frimpong this paved a way for the emergence of other pageants in the country such as Ghana's Most Beautiful (GMB) pageant.

\section{Conceptual Frame of GMB Pageant}

Major components of Ghana's Most Beautiful Pageant (GMB) are illustrated below: the frame clearly illustrates elements including the relationships.

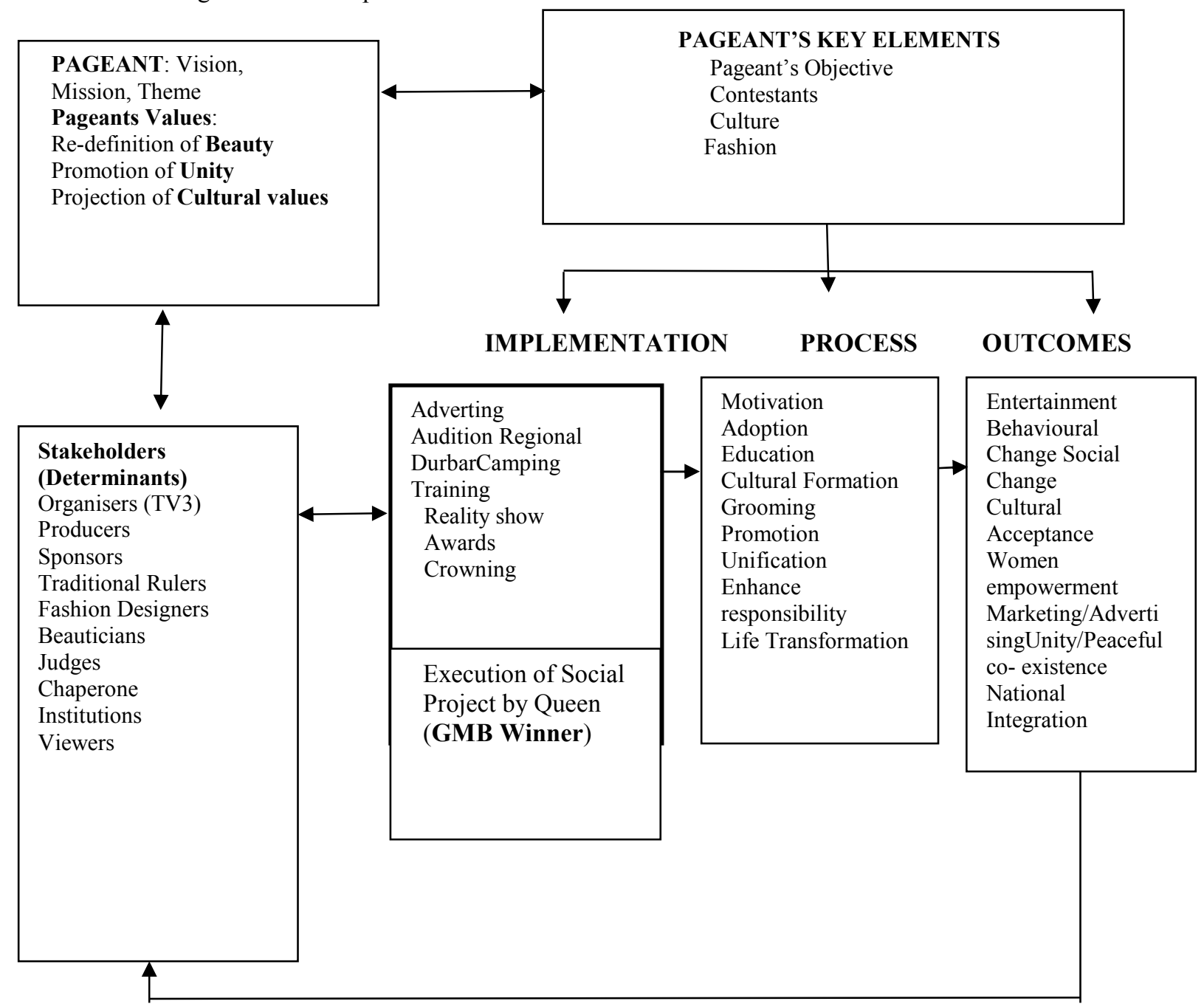

Figure 1. The Conceptual Frame of Ghana's Most Beautiful Pageant Source; Field data

\subsection{Stakeholders of GMB Pageant}

The stakeholders of Ghana's Most Beauty pageant were categorized into three main groups: The first group consisted mainly of organizers of the pageant namely TV3, judges, producers and contestants. Those who played key roles in the dressing and grooming of contestants culturally such as fashion designers, chaperones, traditional rulers and past queens form the second set while the third group were the general public who contributed to the viewing, selection and crowning of the Queen. These are viewers and all who perform various roles in the pageant such as viewing, voting, sponsoring and playing the role of resource persons. All participants 
from the three groups perform significant roles in achieving the pageant objectives of portraying Ghanaian cultural values and promoting unity.

Regional representatives (contestants), viewers, and the organizers were all significant characters of the pageant. The young ladies compete to become Ghana's Most Beautiful Queen through their costumes, talents, physique, skills, aesthetics, style, and values, representing a symbolic package of the Ghanaian culture and fashion.

The above stakeholders established (GMB) with the theme: "Redefining Beauty to Promote National Unity and Development" and the projection of cultural values.

Key Elements of Pageant

3.2.1 Pageant Objective

Ghana's Most Beautiful pageant consists of an exhibition of activities aimed at showcasing Ghanaian beauty from the cultural and traditional points of view (TV3 2012 Report on GMB). Over the years it has engaged the attraction of entertainment and fashion to bring Ghanaian cultural values into display. Objectives of the television station were:

- To unearth great skills and abilities or talents of young ladies in Ghana.

- To bring fore the various Ghanaian cultures.

- To foster tolerance among cultures and build bridges that unite the country.

- Re-position the youth to appreciate the beauty of customs and traditions.

- To unearth beauty that reflects the total beauty and hospitality of Ghanaians.

- To educate viewers, push for developmental agenda and promote the rich endowments of Ghanaian culture worldwide (TV3 2012 report on GMB).

\subsubsection{GMB Contestants}

The GMB pageant searches Ghanaian ladies with high potentials whose ages range from 20 to 30 years. It occasionally includes married women with required qualities to participate since its main objective is to promote cultural values, redefine beauty for the country's development. The 2012 report of GMB and in separate interviews during audition on $28^{\text {th }}$ August 2017 with three organizing members, it was revealed that ladies of the GMB pageant among other things must possess characteristics such as being:

1. Literate and fluent in English

2. Fluent in local language of her locality

3. Bold and articulate

4. Adventurous

5. Dynamic and talented

6. At least $5.5 \mathrm{ft}$ tall

7. Well-built and rounded but not fat and,

8. Well-versed in the cultural values of Ghana

The pageant believed such values would enable the achievement of its objectives. Having been established in 2007. Ghana's Most Beautiful pageant (GMB) was an insightful culturally educative pageant with national patronage. This reality show emanated from a 45-minute television programme on a widely broadcast national station on Ghanaian culture titled "Akwaaba". Later the programme was extended to all the then ten regions of Ghana for a wider coverage of the Ghanaian culture with the name "Ghana's Most Beautiful", a pageant welcomed and participated by all.

\subsubsection{Pageant Cultural Values}

Ghana's Most Beautiful focuses primarily on "cultural values". Potential contestants come from the numerous ethnic groups in all 16 regions of Ghana. It also seeks to re-define Ghanaian beauty; promote cultural awareness and preservation of all regions of Ghana through the concept of fashion among other things. It is staged to reunite the nation by showcasing national distinctiveness and pride, through exhibition of Ghanaian culture.

The pageant values contestants' sound mind, inner self and awareness on their culture. According to GMB 2012 report, TV3 believes selecting a woman would serve as the symbol of culture, tradition, grace, power, elegance and national pride of Ghana. The female gender would not only expose Ghanaian cultural values but also represent its beauty form and fashion.

Contestants are endorsed by their traditional leaders as ladies of character who are found fit to display traditions, cultural rites and exhibit the most beautiful sights of their regions. Participants are destined to go through a thirteen-week encounter displaying their culture. The regional representatives are evicted based on performance and votes from the public. A process which ensures ladies selected to remain in the contest have the right qualities to impact on people's lives as required of the fashion concepts.

Though beauty pageants are invariably all about beauty and character, GMB pageant seems a bit different in that its main aim is the portrayal of cultural tradition and possible education on Ghanaian values which distinguishes it from others, local and international pageants. 


\subsubsection{Fashion}

Fashion is the most curial catalyst used in beauty pageants for positive results since it is classified as a utilitarian art form which combines aesthetics with the functionality of an item (Crawford, 2017). It is a kind of art in which a society is scrutinized through the lens of beauty and quality. It usually related with the idea of creating something distinctive and desirable with constant newness in terms of beauty, style, and glitz. Beauty pageants as associates of fashion must always move hand in hand not only in the designing of clothing but also in the formulating of policies appropriate for pageants. The two in general are not only a social, psychological, and cultural phenomenon, but also and above all, a social-economic phenomenon. There is therefore the need to ensure that the principles and concepts of fashion are adhered to in beauty pageant organizations to produce excellent results. Although personal taste in garment design is important, it must be compared to a complex system of social tastes constantly syncing with time and place. Consequently, adapting the fashion concept should not only maintain the norm but bring about creativity and innovation, hence its suitability for beauty pageant practices.

\subsection{Pageant Activities}

\subsubsection{Pageant Implementation}

Within the pageant, each participant must go through series of activities, including an audition, a regional durbar, in-house camping, training, a reality show, judging and voting, award winning, and final crowning of the queen. The chosen winner takes responsibility of a social project in a specific area of her choice within the borders of Ghana.

The pageant's activities in 2016, 2017 and 2018, which included auditions and regional durbars, were held across the country and adorned with culture and traditional fashion. Traditional rulers, fashion designers, cultural groups, beauticians, parents, elders, youth, and others were among those in attendance. The event was normally televised on a popular television station (TV3) and was watched by millions of people across the country. While auditions and regional durbars were held in selected districts, municipalities, and metropolises throughout each region, the rest of the activities were held at the TV3 Station in Accra, Ghana's capital. The reality shows were filmed in front of viewers who cheered contestants and voted for their favourites.

Activities of pageants were aimed at achieving main objective of event. Balogun, (2012) stated that in emerging nations, beauty pageants perform important dual roles by both creating more cosmopolitan view of femininity that firmly positions a nation in the international arena and unifying vision of a country. Preserving culture through beauty has always been the dream of every nation but is normally interrupted by global fashion. Crawford et al $(2008$, p.61) stated that "beauty pageants represent and reflect not only social constructions of gender but also nationalism, morality, modernization and globalization". Within the concept of fashion, contestants are required to give several presentations on culture such as dressing, dancing, poetry recitals, singing, etc. in all activities.

3.3.2 Pageant Process

A queen who bears the characteristics of her societies as indicated in King-O'Riain (2008) is chosen as a symbolic representation of a collective identity of her people to a larger, often national audience. Most processes in the pageant were tailored towards entertaining, educating, exhibiting culture and fashion. Grooming and life transformation were also observed making it pertinent to conclude that the pageant's main objective was being achieved.

\subsubsection{Pageant Outcomes}

It was discovered that the GMB pageant promoted the adoption of values, provided education through some cultural expressions, enhanced good grooming, and promote life transformations. In all the reality shows in August 2017, 98\% of participants confirmed they were entertained, educated, and relieved of stress. It was certain that the outcome of GMB events could result in life transformations, social change, business promotions, cultural acceptance, unity/peaceful co-existence, women empowerment, national unity and social integration. Ghana's Most Beautiful pageant also has traits associated to its practices such as the following.

\subsubsection{Adoption of Values}

In finding out the extent to which viewers were motivated to accept and adopt the pageant values as part of their culture, it was indicated that the pageant had the potentials of uniting the nation through its display of culture and advocation for developmental agenda; since, it called for people to pause, reflect, judge the society and self on certain practices. The pageant also fostered tolerance among cultures and built bridges that unite the nation. Beliefs on culture had changed which also contributed to the current reflective change in the Ghanaian world of fashion. The pageant's focus on regional culture was critical in uniting Ghanaians and its encouragement for modesty, poise and good morals. Tourism in Ghana was also promoted through the pageant. Change was implicit and critical to the fashion process which occurred over time including change in the object, change among the individuals adopting, and change in the level of acceptance of the various competing fashion objects. 


\subsubsection{Education on Cultural Values}

GMB pageant used its art-portrayed customs and traditions to preserve special identity of all tribes of Ghana. Cultural consciousness was gained through exhibition of cultural skills of various regions. Findings also affirmed that GMB pageant brings to the fore the various Ghanaian cultures that were undiscovered. There was continuous modification of culture through GMB and the promotion of rich endowments of Ghanaian culture. Practices learnt in the pageant were relevant to the Ghanaian society. Clothing worn during GMB reality show was in line with Ghanaian culture but occasionally deviated. Poetry, drama, music, painting, dance, of all arts move people powerfully such as indicated in Plato's theory that art is powerful and can stir up our emotions. This is with the fact that art can strongly influence behaviour, and even character. For that reason, Plato insisted that it should be a weapon in educating young citizens as found in GMB pageant. Plato also advised that it should be strictly censored to present only the "good" because it could also be a dangerous tool.

The social characteristics of the pageant constitute the critical motivations for object acceptance or its process. Sproles' theory cited in Karunaratne, 1917 stated that the process of fashion art is the emergence of the object as an accepted fashion in Society. The pageant educates the public and has what it takes to inform the societies on vital issues and social vices. It ignores negative social practices while concentrating on good ones.

\subsubsection{Motivation}

The fashion process represents a dynamic mechanism by which the object ultimately emerges as an accepted or rejected fashion (Karunaratne, 1917). The fashion process is considered as an interacting behavioural system which is characterized by basic elements such as fashion, culture and aesthetics. In the case of GMB pageant, such elements involved were assessed by viewers and in due course got motivated. There was enthusiasm on the part of the viewers as they watched the event on television and during durbars. Traditional rulers claimed they developed interest for the pageant when it was certain that other cultural values could be learnt through it. The youth indicated they never knew some cultural practices until GMB came. Viewers would accept GMB's fashion in their day-to-day lifestyle or behavioural patterns if activities of the pageant were in line with their cultural beliefs.

\subsubsection{Entertainment}

The event used the attraction of entertainment and fashion to bring fashionable traditional costuming to bear. Ladies were taken through appropriate dressing, application of make-ups and modelling. Contestants presented themselves in free style, casual and evening wear designed in traditional cloth.

The fashion aspect of the event promotes patronage of locally made products (traditional clothing) which goes a long way to enhance the economy. Fashion shows enable contestants to portray their African beauty in various clothing including the traditional woven ones from Ghana. This was confirmed in interviews with randomly selected participants who revealed that the local clothing started gaining recognition when GMB gained grounds.

The Ghana's Most Beautiful pageant has since its inception, besides the entertaining activities, fostered socio-cultural relationship amongst communities in the country and promoted harmonious existence. The pageant educates viewers, pushes for developmental agenda and promotes the rich endowments of Ghanaian culture worldwide. Again, contestants choose to work on a project and problems identified as drawbacks on their region's development.

\subsubsection{Women Empowerment}

Education of the Ghanaian youth on certain cultural practices of the nation was explicitly clear in the activities of the pageant since contestants emphasized significant traditional practices. The impact on community development through the education of viewers pushes for a developmental agenda and the promotion of the rich endowments of Ghanaian culture.

According to a veteran actor, Oscar Provencal, popularly known as "Inspector Bediako", GMB has over the years produced responsible ladies who are doing well by contributing to the development of our society (In an interview with Showbiz, in 2017).

The Ghanaian young women were empowered by the GMB pageant through the exhibition of talents and building of confidence levels. Tolerance for other cultures was appreciated following grooming on how to coexist. Thus, the ten contestants returned home well-groomed to fit into the society; not only did they relate well with other contestants but also with people from all walks of life (a contestant stated in 2017).

Most contestants attested they were challenged to move out of the norm by performing tasks of the male gender. This provided the young ladies the opportunity to move out of their comfort zones in order to achieve something extraordinary. The pageant molded young ladies (contestant) to be adventurous, patient and persistent in all situations.

\section{Conclusion}

The concept of the pageant was all rooted in Ghanaian values with some occasional practices of foreign cultures even though its mission and focus were clearly defined. The programme was full of educative scenes, motivated 
activities, and potential adoption of values and life transformation. The concept was clearly articulated from beginning to end with stakeholders playing vital roles in achieving the main objectives. Traditional rulers who are the custodians of the country's culture were seen fully participating in the event. Scoring assigned by both judges and voters especially during the grand finales formed the key to the nominations of the ultimate winner. Contestants were empowered to take up various roles in the community. Both subjective and objective scoring made overall selection of queen very appropriate. It is recommended that GMB continues to review its activities each year to ensure its relevant to the society.

\section{References}

Balogun, O.M., 2012. Cultural and cosmopolitan: Idealized femininity and embodied nationalism in Nigerian beauty pageants. Gender \& Society, 26(3), pp.357-381.

Banet-Weiser, S., (1999). The most beautiful girl in the world: Beauty pageants and national identity. Univ of California Press

Caves, R.E., (2000). Creative industries: Contracts between art and commerce (No. 20). Harvard University Press.

Chatterjee, A. and Vartanian, O., (2016). Neuroscience of aesthetics. Annals of the New York Academy of Sciences, 1369(1), pp.172-194.

Chatterjee, I. (2016). Women, Monastic Commerce, and Coverture in Eastern India circa 1600-1800 CE. Modern Asian Studies, 50(1), 175-216.

Cope, J., \& Maloney, D. (2016). Fashion promotion in practice (Vol. 60). Bloomsbury Publishing.

Coughlin, S., (2018). Athenaeus of Attalia on the Psychological Causes of Bodily Health. In Mental Illness in Ancient Medicine (pp. 107-142).

Crawford, M. N. (2017). Black Post-Blackness: The Black arts movement and twenty-first-century aesthetics. University of Illinois Press.

Crawford, M., Kerwin, G., Gurung, A., Khati, D., Jha, P. and Regmi, A.C., (2008). Globalizing beauty: Attitudes toward beauty pageants among Nepali women. Feminism \& Psychology, 18(1), pp.61-86.

Frimpong, F. A. "Ghana's Most Beautiful: 10 Years of Cultural and Traditional Education” Showbiz Tv 3 News October 19, 2016.

Karunaratne, P.V.M., (2017). Meanings of Fashion: Context Dependence. International Journal of Multidisciplinary Studies, 3(2).

King - O'Riain, R.C., (2008). Making the perfect queen: The cultural production of identities in beauty pageants. Sociology Compass, 2(1), pp.74-83.

Langlois, J.H., Kalakanis, L., Rubenstein, A.J., Larson, A., Hallam, M. and Smoot, M., (2000). Maxims or myths of beauty? A meta-analytic and theoretical review. Psychological bulletin, 126(3), p.390.

Swale Simon. Conceptual fashion. (ed) in Stupples, Polly, and Venis Jane. Art and Design: History, Theory, Practice Cambridge Scholars Publishing Lady Stephenson Library, NE6 2PA, UK British. ISBN (10): 15275-0307. 